\title{
Religious Moderation in Indonesian Islamic Scholars Articles
}

\author{
Abdul Malik ${ }^{1 *}$, Muhammad Alwi HS ${ }^{2}$, M. Anwar Hindi ${ }^{3}$ \\ 1,3Universitas Al-Asy'ariyah Mandar, Sulawesi Barat, Indonesia \\ ${ }^{2}$ STAI Sunan Pandanaran Yogyakarta, Indonesia \\ *Corresponding author. Email: abdulmalik@mail.unasman.ac.id
}

\begin{abstract}
The Indonesian Minister of Religion, Lukman Hakim Saifuddin, Fachrul Razi, and Yaqut Cholil Qoumas, consistently offer bearings to the Indonesian public to apply strict balance a common responsibility. One of the significant components of the execution of religious moderation is done by Indonesian Islamic scholars in the form of reviewing journal articles. This article analyzes religious moderation in Indonesian Islamic scholars recorded in the form of journal articles from edition of 2016 up to the edition of 2020. Finally, this article concludes that Indonesian Islamic scholars are active in responding to the issue of religious moderation. The endeavors of this scholar are done with an assortment of viewpoints and degrees, beginning from the Indonesian circle by and large, the Indonesian government, Islamic people group associations, education, places of worship, online media, to the Covid-19 pandemic issues. Thus, Indonesian Islamic scholars have put forth significant commitments to attempts to react, spread, keep up with and foster religious moderation in Indonesia, particularly since 2016-2020.
\end{abstract}

Keywords: Indonesian Islamic scholars, Religious Moderation, Journal Articles.

\section{INTRODUCTION}

Radicalism and terrorism alongside other selective perspectives and activities are considered to upset and compromise the uprightness of relations among religion and the state in Indonesia. The present circumstance is viewed as upsetting human existence, both as far as religion and mankind. In spite of the fact that it can't be affirmed, the vast majority of these terrorist developments originate from a strict arrangement that is extremist, select, and dismisses the presence of disciples of different religions. Therefore, one of the concrete steps that are considered effective in dismissing, reducing, or eliminating various acts of radicalism and terrorism is to spread religious understanding moderately. The issue of religious moderation has always been a national issue, as in the direction of Lukman Hakim Saifuddin, Indonesian Religion Minister 2014-2019 that religious moderation must be a shared commitment in making it happen [1]. Lukman Hakim's direction continued until the leadership of Fachrul Razi and Yaqut Cholil Qoumas.

The responsibility of Muslims has turned into a unique worry in the investigation of Indonesian scholars. This is proven by the holding of different insightful plans that make the issue of strict balance a major subject, both at the public and global levels. For example, the Annual International Conference on Islamic Studies (AICIS), the agenda of academics under the auspices of Religion Ministry, during 2018 [2] and 2019 [3]. In addition, the response of the attention of Indonesian scholars regarding religious moderation is also seen in the form of the publication of journal articles. This publication section coincides with the obligation of scholars to publish their scientific works in the form of journals since 2012, both undergraduate and postgraduate levels, especially doctoral degrees [4], including the journals of every Indonesian Islamic scholars under the auspices of Religion Ministry. The obligation to publish scientific papers above is based on reference, at least, in three laws. First, Law Number 12 of 2012 concerning Higher Education. Second, Regulation of Research Minister, Technology and Higher Education Number 50 of 2018 concerning Amendments to Regulation of Research Minister, Technology and Higher Education Number 44 of 2015 concerning National Standards for Higher Education. Third, Regulation of Research Minister, Technology, and Higher Education Number 9 of 2018 concerning Accreditation of Scientific Journals.

The study of undergraduate thought in the form of journal articles related to Islamic studies has not received much attention in research. As far as the author searches, only a few studies have discussed it, namely Fatimah Fatmawati's research (2020) on "Studi Penelitian Tafsir di Indonesia (Pemetaan Karya Tafsir Indonesia Periode 2011-2018) " [5], Hariyah's research (2016) entitled "Research Trends in Islamic Studies on Journal of Research and Development and Training Center Ministry of Religious Affairs: Using CoWords" [6], Nailil Huda and Ade Pahrudin's research (2018) which examines the "Orientasi Kajian Hadis Kontemporer Indonesia (Studi Artikel E-Jurnal dalam Portal Moraref 2015-2017)" [7]. Even though the position of journal articles is very important in scientific development in the academic 
world, including at state Islamic campuses throughout Indonesia. Therefore, this article will discuss Islamic studies in journal articles by scholars from state Islamic campuses that have not been touched by focusing on the phenomenon of religious moderation during 2016-2020.

The taking of Indonesian Islamic scholars here is to show the various significant roles of scholars in the campus environment under the auspices of the Indonesian Religion Ministry, which has been (and in the future) trying to present religious moderation to the community of Indonesia. As for the selection of 2016-2020 as the year of publishing journal articles, this is generally the journals relying on references to journal articles about the last five years. The five-year limit in journal articles is useful for presenting the latest and updated articles so that the scientific process is always visible in its development. From here, the formulation of the problem to be answered is what is the scope of the study by Indonesian Islamic scholars regarding religious moderation as stated in the form of journal articles in the first 2016 to second editions of 2020 ?

\section{THE CONCEPT OF RELIGIOUS MODERATION: AN INTRODUCTION}

The term religious moderation consists of two words, namely 'moderation' and 'religious', where the word moderation itself has two meanings, namely reducing violence and avoiding extremes [8]. Meanwhile, the word religious is an adjective that contains the meaning of embracing or embracing religion [9]. The Religion Ministry itself says that religious moderation will actualize noble religious and cultural values, personal life, family, community, nation, and state, so that there are no clashes, arbitrariness, discomfort, and so on [10].

In Arabic, moderate is often interpreted as the word Al-Washathiyah, where Al-Salabi interprets it with several understandings, namely First from the root wasth, in the form of dharaf, which means baina (between). Second, from the root word wasatha, which contains many meanings, including: first in the form of isim (noun) which contains meaning between two ends; the second is a meaningful trait (khiyar) chosen, especially, the best; the third wasath which means al-'adl or fair; the four wasaths can also mean something that is between the good (jayyid) and the bad (radi') [11]. Similar to the meaning of Al-Sallabi, Hashim Kamali analyzed Al-Washathiyyah as synonyms with the words tawassut, i'tidal, tawazun, and iqtisad. This moderation term is closely related to justice, and it means choosing a middle position between the extremities. The opposite of $A l$ Wasathiyyah is Tatarruf, which denotes a tendency towards the periphery, extremism, radicalism, and exaggeration [12].

In the book on Religious Moderation, the work of the Indonesian Religion Ministry, also makes justice the basic principle of moderation, in addition to the principle of balance - among the balance of reason and revelation, physical and spiritual, rights and obligations, and so on [13]. Furthermore, the principles of justice and balance then give birth to the basis for religious moderation which is sole to God Almighty.
This awareness of godliness to the One then raises awareness of the self that is a servant and surrendered, so that he is a slave to others. From this arises the realization that humans, with their duties as servants of God on earth (Al-Baqarah: 30), are obligatory upon them to maintain balance (moderate), including in religion [14].

\section{INDONESIAN ISLAMIC SCHOLARS STUDY ON RELIGIOUS MODERATION}

The author found many articles written by Indonesian Islamic scholars throughout the first edition of 2016 to 2020. Throughout the author's search, it is found twenty-seven (27) journal articles written by Indonesian Islamic scholars, which were dominated by IAIN and UIN. Here, the author will describe the classification of the journal parts that are considered most important in the article, namely the title of the article, the author, the author's agency, the type of article, and the journal in which the article is published. In simple terms, the authors' findings related to these articles can be seen in the following table:

Table 1. Literature Review

\begin{tabular}{|c|c|c|c|c|c|}
\hline No & Author & \begin{tabular}{|c|} 
State \\
Islamic \\
Uni
\end{tabular} & Title & Type & Published \\
\hline 1 & Darlis & $\begin{array}{l}\text { IAIN } \\
\text { Palu }\end{array}$ & $\begin{array}{l}\text { Peran Pesantren } \\
\text { As'adiyah } \\
\text { Sengkang dalam } \\
\text { Membangun } \\
\text { Moderasi Islam } \\
\text { di Tanah Bugis } \\
\text { (Sebuah } \\
\text { Penelitian Awal) }\end{array}$ & $\begin{array}{c}\text { Library } \\
\text { Research }\end{array}$ & $\begin{array}{c}\text { Al- } \\
\text { Misbah, } \\
\text { Vol. 12, } \\
\text { No. 1, } \\
\text { 2016. }\end{array}$ \\
\hline 2 & $\begin{array}{c}\text { Zakiyah } \\
\text { Darajat }\end{array}$ & \begin{tabular}{|l} 
UIN \\
Syarif \\
Hidayat \\
ullah \\
Jakarta
\end{tabular} & $\begin{array}{c}\text { Muhammadiyah } \\
\text { dan NU: Penjaga } \\
\text { Moderatisme } \\
\text { Islam di } \\
\text { Indonesia }\end{array}$ & $\begin{array}{c}\text { Library } \\
\text { Research }\end{array}$ & $\begin{array}{l}\text { Hayulah: } \\
\text { Indonesian } \\
\text { Journal of } \\
\text { Multidisci } \\
\text { plinary } \\
\text { Islamic } \\
\text { Studies, } \\
\text { Vol. 1, No. } \\
1,2017 .\end{array}$ \\
\hline 3 & Darlis & $\begin{array}{l}\text { IAIN } \\
\text { Palu }\end{array}$ & $\begin{array}{c}\text { Mengusung } \\
\text { Moderasi Islam } \\
\text { di tengah } \\
\text { Masyarakat } \\
\text { Multi Kultural } \\
\end{array}$ & $\begin{array}{l}\text { Library } \\
\text { Research }\end{array}$ & $\begin{array}{c}\text { Rausyan } \\
\text { Fikr, Vol. } \\
\text { 13, No. 2, } \\
2017 .\end{array}$ \\
\hline 4 & $\begin{array}{l}\text { Mohamm } \\
\text { ad Deny } \\
\text { Irawan }\end{array}$ & \begin{tabular}{|c|} 
UIN \\
Syarif \\
Hidayat \\
ullah \\
Jakarta
\end{tabular} & \begin{tabular}{|c|} 
Islam \\
Wasatiyyah: \\
Refleksi Antara \\
Islam Modern \\
dan Upaya \\
Moderasi Islam
\end{tabular} & $\begin{array}{l}\text { Library } \\
\text { Research }\end{array}$ & $\begin{array}{c}\text { Tajdid, } \\
\text { Vol. XVI, } \\
\text { No. 2, } \\
2017 .\end{array}$ \\
\hline 5 & $\begin{array}{l}\text { Mustiqow } \\
\text { ati } \\
\text { Ummul } \\
\text { Fithriyyah } \\
\text { dan } \\
\text { Muhamm } \\
\end{array}$ & \begin{tabular}{|l} 
UIN \\
Sultan \\
Syarif \\
Kasim \\
Riau,
\end{tabular} & $\begin{array}{c}\text { Quo Vadis } \\
\text { Ormas Islam } \\
\text { Moderat } \\
\text { Indonesia? } \\
\text { Menoropong } \\
\text { Perang NU- } \\
\end{array}$ & $\begin{array}{l}\text { Library } \\
\text { Research }\end{array}$ & $\begin{array}{l}\text { Politea: } \\
\text { Jurnal } \\
\text { Pemikiran } \\
\text { Poltik } \\
\text { Islam, Vol. }\end{array}$ \\
\hline
\end{tabular}




\begin{tabular}{|c|c|c|c|c|c|}
\hline & $\begin{array}{l}\text { ad Saiful } \\
\text { Umam }\end{array}$ & $\begin{array}{l}\text { IAIN } \\
\text { Kediri }\end{array}$ & $\begin{array}{c}\text { Muhammadiyah } \\
\text { di Era Revolusi } \\
\text { Industri } 4.0\end{array}$ & & $\begin{array}{c}\text { 1, No. 1, } \\
2018 .\end{array}$ \\
\hline 6 & Muktafi & $\begin{array}{c}\text { UIN } \\
\text { Sunan } \\
\text { Ampel } \\
\text { Suraba } \\
\text { ya }\end{array}$ & $\begin{array}{c}\text { Dinamika } \\
\text { Pengarusutamaa } \\
\text { n Moderasi Islam } \\
\text { di Masjid } \\
\text { Nasional Al- } \\
\text { Akbar Surabaya } \\
\text { (MAS) }\end{array}$ & $\begin{array}{c}\text { Field } \\
\text { Research }\end{array}$ & \begin{tabular}{|c} 
Islamika \\
Inside: \\
Jurnal \\
Keislaman \\
dan \\
Humaniora \\
, Vol. 4, \\
No. 1, \\
2018.
\end{tabular} \\
\hline 7 & $\begin{array}{c}\text { Nurul } \\
\text { Faiqah } \\
\text { and Toni } \\
\text { Pransiska }\end{array}$ & \begin{tabular}{|c} 
UIN \\
Sunan \\
Kalijag \\
a, Stai \\
Sunan \\
Pandan \\
aran \\
Yogyak \\
arta
\end{tabular} & $\begin{array}{c}\text { Radikalisme } \\
\text { Islam VS } \\
\text { Moderasi Islam: } \\
\text { Upaya } \\
\text { Membangun } \\
\text { Wajah Islam } \\
\text { Indonesia yang } \\
\text { Damai }\end{array}$ & $\begin{array}{l}\text { Library } \\
\text { Research }\end{array}$ & $\begin{array}{l}\text { Al-Fikra: } \\
\text { Jurnal } \\
\text { Ilmiah } \\
\text { Keislaman } \\
\text {,Vol. 17, } \\
\text { No. 1, } \\
2018 .\end{array}$ \\
\hline 8 & $\begin{array}{l}\text { Ahmad } \\
\text { Agis } \\
\text { Mubarok } \\
\text { dam Diaz } \\
\text { Gandara } \\
\text { Rustam }\end{array}$ & $\begin{array}{l}\text { UIN } \\
\text { Sunan } \\
\text { Kalijag } \\
\text { a } \\
\text { Yogyak } \\
\text { arta }\end{array}$ & $\begin{array}{l}\text { Islam Nusantara: } \\
\text { Moderasi Islam } \\
\text { di Indonesia }\end{array}$ & $\begin{array}{l}\text { Library } \\
\text { Research }\end{array}$ & $\begin{array}{l}\text { Journal of } \\
\text { Islamic } \\
\text { Studies } \\
\text { and } \\
\text { Humanitie } \\
\text { s, Vol. 3, } \\
\text { No. 2, } \\
2018 .\end{array}$ \\
\hline 9 & $\begin{array}{c}\text { Ahmad } \\
\text { Fauzi }\end{array}$ & $\begin{array}{c}\text { UIN } \\
\text { Sunan } \\
\text { Gunun } \\
\text { g Djati } \\
\text { Bandun } \\
\text { g }\end{array}$ & $\begin{array}{c}\text { Moderasi Islam, } \\
\text { untuk Peradaban } \\
\text { dan } \\
\text { Kemanusiaan }\end{array}$ & $\begin{array}{l}\text { Library } \\
\text { Research }\end{array}$ & \begin{tabular}{|c} 
Jurnal \\
Islam \\
Nusantara, \\
Vol. 2, No. \\
2, 2018.
\end{tabular} \\
\hline 10 & $\begin{array}{l}\text { Fahrurrozi } \\
\text { and } \\
\text { Muhamm } \\
\text { ad Thohri }\end{array}$ & $\begin{array}{c}\text { UIN } \\
\text { Matara } \\
\mathrm{m}\end{array}$ & $\begin{array}{c}\text { Media dan } \\
\text { Dakwah } \\
\text { Moderasi: } \\
\text { Melacak Peran } \\
\text { Strategis dalam } \\
\text { Menyebarkan } \\
\text { Faham Moderasi } \\
\text { di Situs } \\
\text { Nahdlatul } \\
\text { Wathan On-Line } \\
\text { Situs Kalangan } \\
\text { Netizen Muslim- } \\
\text { Santri }\end{array}$ & $\begin{array}{l}\text { Library } \\
\text { Research }\end{array}$ & $\begin{array}{l}\text { Tasamuh: } \\
\text { Jurnal } \\
\text { Komunika } \\
\text { si dan } \\
\text { Pengemba } \\
\text { ngan } \\
\text { Masyaraka } \\
\text { t Islam, } \\
\text { Vol. 17, } \\
\text { No 1, } \\
2019 .\end{array}$ \\
\hline 11 & $\begin{array}{c}\text { Neny } \\
\text { Muthi'atu } \\
1 \\
\text { Awwaliya } \\
\text { h }\end{array}$ & \begin{tabular}{|} 
UIN \\
Sunan \\
Kalijag \\
a \\
Yogyak \\
arta
\end{tabular} & \begin{tabular}{|c} 
Pondok \\
Pesantren \\
sebagai Wadah \\
Moderasi Islam \\
di Era Generasi \\
Millenial
\end{tabular} & $\begin{array}{l}\text { Library } \\
\text { Research }\end{array}$ & \begin{tabular}{|c} 
Islamic \\
Review: \\
Jurnal \\
Riset dan \\
Kajian \\
Keislaman \\
, Vol. 8, \\
No. 1, \\
2019. \\
\end{tabular} \\
\hline 12 & $\begin{array}{c}\text { Ari } \\
\text { Wibowo }\end{array}$ & \begin{tabular}{|c|} 
IAIN \\
Syaikh \\
Abdura \\
hman \\
Siddiq \\
Bangka
\end{tabular} & $\begin{array}{c}\text { Kampanye } \\
\text { Moderasi } \\
\text { Beragama di } \\
\text { Facebook: } \\
\text { Bentuk dan } \\
\text { Strategi Pesan }\end{array}$ & $\begin{array}{l}\text { Library } \\
\text { Research }\end{array}$ & \begin{tabular}{|l} 
Edugama: \\
Jurnal \\
Kependidi \\
kan dan \\
Sosial \\
Keagamaa
\end{tabular} \\
\hline
\end{tabular}

\begin{tabular}{|c|c|c|c|c|c|}
\hline & & $\begin{array}{c}\text { Belitun } \\
\mathrm{g}\end{array}$ & & & \begin{tabular}{|c} 
n, Vol. 5, \\
No. 1, \\
2019.
\end{tabular} \\
\hline 13 & \begin{tabular}{|} 
Busyro, \\
Aditiya \\
Hari \\
Ananda, \\
Tarihoran \\
Sanur \\
Adlan
\end{tabular} & $\begin{array}{l}\text { IAIN } \\
\text { Bukit } \\
\text { Tinggi }\end{array}$ & $\begin{array}{c}\text { Moderasi Islam } \\
\text { (Wasathiyyah) di } \\
\text { Tengah } \\
\text { Pluralisme } \\
\text { Agama Indonesia }\end{array}$ & $\begin{array}{l}\text { Library } \\
\text { Research }\end{array}$ & $\begin{array}{l}\text { Fuadana: } \\
\text { Jurnal } \\
\text { Kajian } \\
\text { Keagamaa } \\
\text { n dan } \\
\text { Kemasyara } \\
\text { katan, Vol. } \\
\text { 3, No. 1, } \\
\text { 2019. }\end{array}$ \\
\hline 14 & $\begin{array}{c}\text { Ahmad } \\
\text { Khoiri }\end{array}$ & \begin{tabular}{|l} 
IAIN \\
Madura
\end{tabular} & $\begin{array}{c}\text { Moderasi Islam } \\
\text { dan Akulturasi } \\
\text { Budaya: } \\
\text { Revitalisasi } \\
\text { Kemajuan } \\
\text { Peradaban Islam } \\
\text { Nusantara }\end{array}$ & $\begin{array}{l}\text { Library } \\
\text { Research }\end{array}$ & $\begin{array}{c}\text { Islamadina } \\
\text { : Jurnal } \\
\text { Pemikiran } \\
\text { Islam, Vol. } \\
\text { 20, No. 1, } \\
2019 .\end{array}$ \\
\hline 15 & $\begin{array}{l}\text { Mohamad } \\
\text { Fahri and } \\
\text { Ahmad } \\
\text { Zainuri }\end{array}$ & $\begin{array}{l}\text { Kement } \\
\text { rian } \\
\text { Agama } \\
\text { RI, } \\
\text { UIN } \\
\text { Raden } \\
\text { Fatah } \\
\text { Palemb } \\
\text { ang } \\
\end{array}$ & $\begin{array}{c}\text { Moderasi } \\
\text { Beragama di } \\
\text { Indonesia }\end{array}$ & $\begin{array}{l}\text { Library } \\
\text { Research }\end{array}$ & $\begin{array}{l}\text { Intizar, } \\
\text { Vol. 25, } \\
\text { No. 2, } \\
\text { Desember } \\
2019\end{array}$ \\
\hline 16 & $\begin{array}{c}\text { Hamka } \\
\text { Husein } \\
\text { Hasibuan }\end{array}$ & \begin{tabular}{|c} 
UIN \\
Sunan \\
Kalijag \\
a \\
Yogyak \\
arta
\end{tabular} & $\begin{array}{c}\text { Moderasi Islam, } \\
\text { Pencantuman } \\
\text { Penghayat } \\
\text { Kepercayaan di } \\
\text { Kolom KTP/KK } \\
\text { dalam Nalar } \\
\text { Maqasid }\end{array}$ & $\begin{array}{l}\text { Library } \\
\text { Research }\end{array}$ & $\begin{array}{l}\text { Al-Qalam: } \\
\text { Journal of } \\
\text { Islam and } \\
\text { Plurality, } \\
\text { Vol. 4, No. } \\
\text { 2, 2019. }\end{array}$ \\
\hline 17 & $\begin{array}{c}\text { Betria } \\
\text { Zarpina } \\
\text { Yanti and } \\
\text { Doli } \\
\text { Witro }\end{array}$ & \begin{tabular}{|c|} 
IAIN \\
Kerinci \\
, Jambi
\end{tabular} & \begin{tabular}{|c|} 
Islamic \\
Moderation as a \\
Resolution of \\
Different \\
Conflicts of \\
Religion
\end{tabular} & $\begin{array}{l}\text { Library } \\
\text { Research }\end{array}$ & $\begin{array}{c}\text { Andragogi } \\
\text { : Jurnal } \\
\text { Diklat } \\
\text { Teknis } \\
\text { Pendidikan } \\
\text { dan } \\
\text { Keagamaa } \\
\text { n, Vol. 8, } \\
\text { No. 1, } \\
\text { 2020. }\end{array}$ \\
\hline 18 & $\begin{array}{c}\text { Meirison, } \\
\text { Desmadi } \\
\text { Saharuddi } \\
\mathrm{n}, \\
\text { Rosdialen } \\
\text { a and } \\
\text { Muhamm } \\
\text { ad Ridho }\end{array}$ & \begin{tabular}{|c} 
UIN \\
Imam \\
Bonjol, \\
UIN \\
Syarif \\
Hidayat \\
ullah \\
Jakarta, \\
Univers \\
itas \\
Muham \\
madiya \\
h \\
Sumate \\
ra \\
Barat, \\
UIN
\end{tabular} & $\begin{array}{c}\text { Moderasi Islam } \\
\text { dalam } \\
\text { Kesetaraan } \\
\text { Gender } \\
\text { (Komparasi } \\
\text { terhadap Agama } \\
\text { Yahudi dan } \\
\text { Nasrani) }\end{array}$ & $\begin{array}{l}\text { Library } \\
\text { Research }\end{array}$ & $\begin{array}{c}\text { Jurnal Al- } \\
\text { Ijtimaiyya } \\
\text { h: Media } \\
\text { Kajian } \\
\text { Pengemba } \\
\text { ngan } \\
\text { Masyaraka } \\
\text { t Islam, } \\
\text { Vol. 6, No. } \\
1,2020 .\end{array}$ \\
\hline
\end{tabular}




\begin{tabular}{|c|c|c|c|c|c|}
\hline & & \begin{tabular}{|c} 
Imam \\
Bonjol \\
Padang
\end{tabular} & & & \\
\hline \begin{tabular}{|l|}
19 \\
\end{tabular} & $\begin{array}{l}\text { RR. Wuri } \\
\text { Arenggoa } \\
\text { sih, } \\
\text { Corona } \\
\text { Raisa } \\
\text { Wijayanti }\end{array}$ & $\begin{array}{c}\text { IAIN } \\
\text { Salatig } \\
\text { a }\end{array}$ & \begin{tabular}{|c} 
Pesan \\
Kementrian \\
Agama dalam \\
Moderasi \\
Melalui Media \\
Sosial Instagram
\end{tabular} & $\begin{array}{l}\text { Library } \\
\text { Research }\end{array}$ & $\begin{array}{c}\text { Jurnalisa, } \\
\text { Vol. 6, No. } \\
1,2020 .\end{array}$ \\
\hline 20 & $\begin{array}{l}\text { Saifuddin } \\
\text { Asrori }\end{array}$ & \begin{tabular}{|c|} 
UIN \\
Syarif \\
Hidayat \\
ullah \\
Jakarta
\end{tabular} & $\begin{array}{c}\text { Lanskap } \\
\text { Moderasi } \\
\text { Keagamaan } \\
\text { Santri, Refleksi } \\
\text { Pola Pendidikan } \\
\text { Pesantren }\end{array}$ & $\begin{array}{l}\text { Library } \\
\text { Research }\end{array}$ & $\begin{array}{c}\text { Jurnal } \\
\text { Ilmu } \\
\text { Sosial } \\
\text { Indonesia } \\
\text { (JISI), } \\
\text { Vol. 1, No. } \\
\text { 1, 2020. }\end{array}$ \\
\hline \begin{tabular}{|l|}
21 \\
\end{tabular} & \begin{tabular}{|} 
Abdul \\
Syatar, \\
Muhamm \\
ad Majdy \\
Amiruddi \\
n, Arif \\
Rahman
\end{tabular} & $\begin{array}{l}\text { UIN } \\
\text { Alaudd } \\
\text { in } \\
\text { Makass } \\
\text { ar, } \\
\text { IAIN } \\
\text { Parepar } \\
\text { e, UIN } \\
\text { Alaudd } \\
\text { in }\end{array}$ & \begin{tabular}{|c} 
Darurat \\
Moderasi \\
Beragama di \\
Tengah Pandemi \\
Corona Virus \\
Desease 2019 \\
(Covid-19)
\end{tabular} & $\begin{array}{l}\text { Library } \\
\text { Research }\end{array}$ & $\begin{array}{l}\text { Kuriositas: } \\
\text { Media } \\
\text { Komunika } \\
\text { si Sosial } \\
\text { dan } \\
\text { Keagamaa } \\
\text { n, Vol. 13, } \\
\text { No. 1, } \\
\text { 2020. }\end{array}$ \\
\hline 22 & $\begin{array}{c}\text { M.A. } \\
\text { Hermawa } \\
\mathrm{n}\end{array}$ & $\begin{array}{c}\text { IAIN } \\
\text { Purwok } \\
\text { erto }\end{array}$ & $\begin{array}{l}\text { Nilai Moderasi } \\
\text { Islam dan } \\
\text { Internalisasinya } \\
\text { di Sekolah }\end{array}$ & $\begin{array}{c}\text { Field } \\
\text { Research }\end{array}$ & $\begin{array}{c}\text { Insania, } \\
\text { Vol. 25, } \\
\text { No. 1, } \\
2020\end{array}$ \\
\hline 23 & $\begin{array}{c}\text { Hani } \\
\text { Hiqmatun } \\
\text { nisa and } \\
\text { Ashif Az- } \\
\text { Zafi }\end{array}$ & $\begin{array}{l}\text { IAIN } \\
\text { Kudus }\end{array}$ & $\begin{array}{l}\text { Penerapan Nilai- } \\
\text { nilai Moderasi } \\
\text { Islam dalam } \\
\text { Pembelajaran } \\
\text { Fiqh di PTKIN } \\
\text { Menggunakan } \\
\text { Konsep Problem- } \\
\text { Based Learning }\end{array}$ & $\begin{array}{c}\text { Field } \\
\text { Research }\end{array}$ & $\begin{array}{l}\text { JIPIS, Vol. } \\
29, \text { No. } 1, \\
2020\end{array}$ \\
\hline 24 & $\begin{array}{l}\text { Khalil } \\
\text { Nurul } \\
\text { Islam }\end{array}$ & $\begin{array}{c}\text { UIN } \\
\text { Alaudd } \\
\text { in } \\
\text { Makass } \\
\text { ar }\end{array}$ & $\begin{array}{c}\text { Moderasi } \\
\text { Beragama di } \\
\text { Tengah } \\
\text { Pluralitas } \\
\text { Bangsa: } \\
\text { Tinjauan } \\
\text { Revolusi Mental } \\
\text { Perspektif Al- } \\
\text { Qur'an } \\
\end{array}$ & $\begin{array}{l}\text { Library } \\
\text { Research }\end{array}$ & $\begin{array}{l}\text { Kuriositas: } \\
\text { Media } \\
\text { Komunika } \\
\text { si Sosial } \\
\text { dan } \\
\text { Keagamaa } \\
\text { n, Vol. 13, } \\
\text { No. 1, } \\
2020 \\
\end{array}$ \\
\hline 25 & $\begin{array}{c}\text { A. Jauhar } \\
\text { Fuad }\end{array}$ & $\begin{array}{c}\text { IAI } \\
\text { Tribakt } \\
\text { i Kediri }\end{array}$ & $\begin{array}{c}\text { Akar Sejarah } \\
\text { Moderasi Islam } \\
\text { pada Nahdlatul } \\
\text { Ulama }\end{array}$ & $\begin{array}{l}\text { Library } \\
\text { Research }\end{array}$ & \begin{tabular}{|c} 
Tribakti: \\
Jurnal \\
Pemikiran \\
Keislaman \\
, Vol. 31, \\
No. 1, \\
2020.
\end{tabular} \\
\hline 26 & $\begin{array}{l}\text { Dany } \\
\text { Miftah M. } \\
\text { Nur, } \\
\text { Mochama } \\
\text { d, and } \\
\text { Risha } \\
\text { Fitriani } \\
\end{array}$ & $\begin{array}{l}\text { IAIN } \\
\text { Kudus }\end{array}$ & $\begin{array}{c}\text { Membumikan } \\
\text { Nilai-nilai } \\
\text { Moderasi Agama } \\
\text { di Masa Pandemi } \\
\text { (dalam Perspektif } \\
\text { IPS) }\end{array}$ & $\begin{array}{l}\text { Library } \\
\text { Research }\end{array}$ & $\begin{array}{l}\text { Harmony, } \\
\text { Vol. 5, No. } \\
2,2020 .\end{array}$ \\
\hline
\end{tabular}

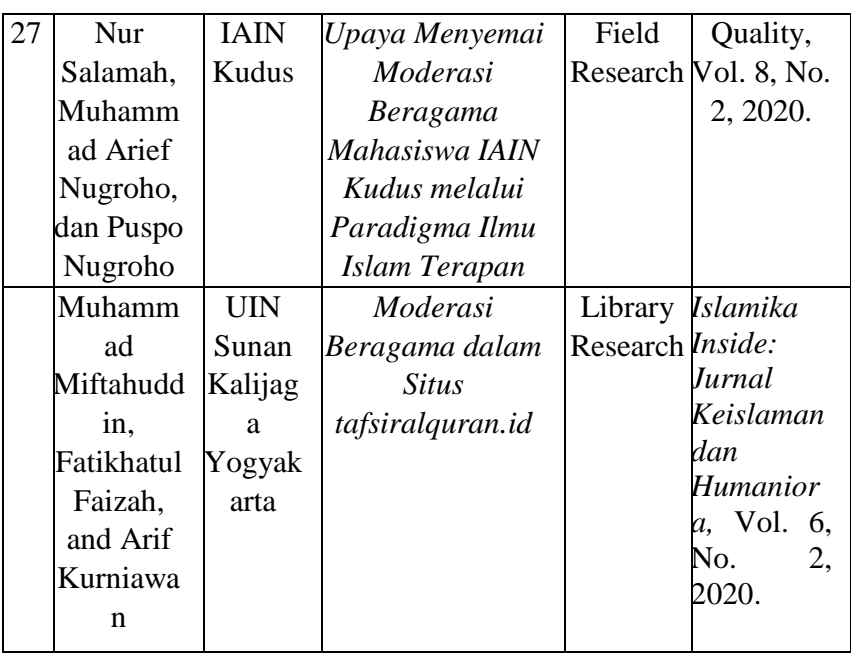

The various articles in the table above provide an understanding that articles on the issue of religious moderation have appeared in 2016 as written by Darlis, a scholar at IAIN Palu. In subsequent editions of the journals, it shows the development or increase in the number of articles from year to year. Here, the articles on religious moderation were the least found in 2016, as written by Darlis. Meanwhile, the most articles were found in 2020, which contained nine articles: (1) Betria Zarpina Yanti and Doli Witro, (2) Meirison, Desmadi Saharuddin, Rosdialena, and Muhammad Ridho, (3) RR. Wuri Arenggoasih, Corona Raisa Wijayanti, (4) Saifuddin Asrori, (5) Abdul Syatar, Muhammad Majdy Amiruddin, Arif Rahman, (6) M.A. Hermawan, (7) Hani Hiqmatunnisa and Ashif Az-Zafi, (8) Khalil Nurul Islam, (9) A. Jauhar Fuad, (10) Dany Miftah M. Nur, Mochamad, and Risha Fitriani, (11) Nur Salamah, Muhammad Arief Nugroho, and Puspo Nugroho, and (12) Miftahuddin, Fatikhatul Faizah, and Arif Kurniawan. The number of articles found from year to year has differences, in 2016 only one article was found, in 2017 two articles were found, in 2018 there were four articles, in 2019 six articles were found, and in 2020, twelve articles were found.

\section{VARIOUS SCOPE OF RELIGIOUS MODERATION IN SCHOLAR'S STUDIES}

Previously, articles that discussed religious moderation were presented, in which they presented studies from various perspectives. It shows that every year, the issue of religious moderation always arises and increases. In addition, the issue of religious moderation in these articles can be classified into several mappings, starting from the Indonesian context in general, Islamic community organizations, educational institutions, to religious moderation in the social media space. First, religious moderation is within the scope of Indonesia in general. In this section, articles related to religious moderation are found in various ways, both field studies and conceptually. At least nine articles on religious moderation were found in different years, from 2017-2020.

Articles on religious moderation related to Islam in Indonesia that were found in 2017 were "Mengusung Moderasi Islam di tengah Masyarakat Multi Kultural" by 
Darlis [15], and "Islam Wasatiyyah: Refleksi Antara Islam Modern dan Upaya Moderasi Islam" by Mohammad Deny Irawan [16]. In 2018 an article on religious moderation was found entitled "Radikalisme Islam VS Moderasi Islam: Upaya Membangun Wajah Islam Indonesia yang Damai" by Nurul Faiqah and Toni Pransiska [17], and an article entitled "Moderasi Islam, untuk Peradaban dan Kemanusiaan" by Ahmad Fauzi [18]. In 2019, an article on religious moderation related to Islam appeared, which was not much different from the article written by Deny Irawan above. The article is "Moderasi Islam (Wasathiyyah) di Tengah Pluralisme Agama Indonesia" by Busyro [19], Aditya Hari Ananda and Tarihoran Sanur Adlan. The next article is "Moderasi Islam dan Akulturasi Budaya: Revitalisasi Kemajuan Peradaban Islam Nusantara" by Ahmad Khoiri [20].

In 2020, the article "Moderasi Beragama di Tengah Pluralitas Bangsa: Tinjauan Revolusi Mental Perspektif AlQur'an" by Khalil Nurul Islam [21] appeared which specifically took the point of view of the Qur'an. Furthermore, the article which is broader in scope is "Moderasi Beragama di Indonesia" by Mohammad Fahri and Ahmad Zainuri (2019) [22] can be positioned as the article with the broadest scope of the two previous articles above. However, the article shows a discussion that is not much different from the article "Moderasi Islam (Wasathiyyah) di Tengah Pluralisme Agama Indonesia" by Busyro, Aditya Hari Ananda, and Tarihoran Sanur Adlan [23] as previously explained. There is almost no novelty found in the article, this is because the description of the discussion and the conclusions reached are very similar to those of Busyro, Aditya Hari Ananda, and Tarihoran Sanur Adlan's articles.

Second, Religious Moderation concerning the Indonesian Government. In this context, two articles were found published in 2019 and 2020. The first article is entitled "Moderasi Islam, Pencantuman Penghayat Kepercayaan di Kolom KTP/KK dalam Nalar Maqasid" by Hamka Husein Hasibuan (2019) [24] and "Pesan Kementrian Agama dalam Moderasi Melalui Media Sosial Instagram" by RR. Wuri Arenggoasih and Corona Raisa Wijayanti (2020) [25]. The two articles take a different perspective, where the first article focuses on a critical analysis of Maqasid Reason for the inclusion of the identity of Believers in the KTP/KK column, while the second is a broadcast of religious moderation preaching by Religion Ministry on social media.

Third, Religious Moderation in the context of Indonesian Islamic Community Organizations. Here, there are four articles that discuss the issue of religious moderation, in 2017 ( 1 article), 2018 ( 2 articles), and in 2020 ( 1 article). In 2017, an article was found entitled "Muhammadiyah dan NU: Penjaga Moderatisme Islam di Indonesia" by Zakiyah Darajat [26]. In 2018 the article "Quo Vadis Ormas Islam Moderat Indonesia? Menoropong Perang NUMuhammadiyah di Era Revolusi Industri 4.0" by Mustiqowati Ummul Fithriyyah and Muhammad Saiful Umam [27], "Islam Nusantara: Moderasi Islam di Indonesia" by Ahmad Agis Mubarok and Diaz Gandara Rustam [28]. As for 2020, an article entitled "Akar Sejarah Moderasi Islam pada Nahdlatul Ulama" was found by A. Jauhar Fuad [29]. The three articles discussed ORMAS Nahdlatul Ulama and Muhammadiyah, and one article on Nahdlatul Ulama.
Fourth, Religious Moderation in the line of education. In this context, the authors found six journal articles discussing religious moderation in the context of education, which appeared in 2016 (1 article), 2019 (1 article), and 2020 (4 articles). The articles are "Peran Pesantren As'adiyah Sengkang dalam Membangun Moderasi Islam di Tanah Bugis (Sebuah Penelitian Awal)" by Darlis (2016) [30], "Pondok Pesantren sebagai Wadah Moderasi Islam di Era Generasi Millenial" by Neny Muthi'atul Awwaliyah ( 2019) [31], "Lanskap Moderasi Keagamaan Santri, Refleksi Pola Pendidika Pesantren" by Saifudin Asrori (2020) [32], "Nilai Moderasi Islam dan Internalisasinya di Sekolah" by MA Hermawan (2020) [33], "Penerapan Nilai-nilai Moderasi Islam dalam Pembelajaran Fiqh di PTKIN Menggunakan Konsep Problem-Based Learning" by Hani Hiqmatunnisa and Ashif Az-Zafi (2020) [34], and "Upaya Menyemai Moderasi Beragama Mahasiswa IAIN Kudus melalui Paradigma Ilmu Islam Terapan” by Nur Salamah, Muhammad Arief Nugroho, and Puspo Nugroho (2020) [35].

Most of the articles above show pesantren as the basis of education which is the object of study of religious moderation. Other education lines are Schools and state Islamic University, all of which only appear in one article each. Furthermore, the study of articles on religious moderation in pesantren is divided into two, namely conceptual studies and field studies (concrete). An article that discusses religious moderation conceptually as done by Neny Muthi'atul Awwaliyah and Saifudin Asrori. Meanwhile, fieldbased articles as done by Darlis. The article on religious moderation in schools was carried out with a conceptual study as carried out by M.A. Hermawan. The moderation of religion at state Islamic University is carried out by field studies as Hani Hiqmatunnisa and Ashif Az-Zafi, and at IAIN Kudus as carried out by Nur Salamah, Muhammad Arief Nugroho, and Puspo Nugroho. Thus, all the articles above not only show the diversity of education lines but also shows the aspect of diversity in the form of study.

Fifth, Religious Moderation at places of Worship. For the context of places of worship, the author only found one article, namely "Dinamika Pengarusutamaan Moderasi Islam di Masjid Nasional Al-Akbar Surabaya (MAS)" by Muktafi (2018) [36]. Sixth, Religious Moderation related to the issue of gender equality, which the author found in the article "Moderasi Islam dalam Kesetaraan Gender (Komparasi terhadap Agama Yahudi dan Nasrani)" by Meirison, Desmadi Saharuddin, Rosdialena and Muhammad Ridho published in 2020 [37]. Seventh, Moderation Religion in the social media space. Regarding religious moderation related to the context of social media, the author found four articles, namely "Pesan Kementerian Agama dalam Moderasi Melalui Media Sosial Instagram" by RR. Wuri Arenggoasih, Corona Raisa Wijayanti (2020) [38], "Media dan Dakwah Moderasi: Melacak Peran Strategis dalam Menyebarkan Faham Moderasi di Situs Nahdlatul Wathan On-Line Situs Kalangan Netizen Muslim-Santri" by Fahrurrozi and Muhammad Thohri (2019) [39] and "Kampanye Moderasi Beragama di Facebook: Bentuk dan Strategi Pesan" by Ari Wibowo (2019) [40]. However, the article written by Wuri and Corona Raisa has been described previously, specifically 
in the sub-chapter of Religious Moderation and the Indonesian Government. The last article is "Moderasi Beragama dalam Situs tafsiralquran.id" by Miftahuddin, Fatikhatul Faizah, and Arif Kurniawan (2020) [41].

Eighth, Religious Moderation concerning the Covid19 Pandemic. In the author's search, two articles were found that discussed religious moderation related to the Covid-19 Pandemic, namely "Darurat Moderasi Beragama di Tengah Pandemi Corona Virus Desease 2019 (Covid-19)" by Abdul Syatar, Muhammad Majdy Amiruddin, Arif Rahman (2020) [42], and "Membumikan Nilai-nilai Moderasi Agama di Masa Pandemi (dalam Perspektif IPS)" by Dany Miftah M. Nur, Mochamad, and Risha Fitriani (2020) [43]. The first article describes concerns over the 'disruption' of religious moderation caused by the spread of the Coronavirus in Indonesia. While the second article seeks to propagate religious teachings related to religious moderation even during the pandemic, this is analyzed from an IPS perspective.

\section{CONCLUSION}

From the different clarifications in the past conversations, a few ends can be drawn. In the first place, Indonesian Islamic scholars are dynamic in reacting to the issue of religious moderation. The scholar's endeavors are completed with different viewpoints and extensions, going from the extent of Indonesia as a rule, the Indonesian government, Islamic people group associations, education, places of worship, web-based media, to the Covid-19 pandemic. The assortment of viewpoints and extensions shows that the investigation of Indonesian Islamic scholars not just makes the issue of strict balance a significant part to be concentrated yet in addition it is interrelated with different issues. Second, the event of different viewpoints and extensions in the Indonesian Islamic scholars concentrate on shows the unmistakable and particular commitment of Indonesian Islamic scholars as a work to react, spread, keep up with and foster strict balance in Indonesia, particularly since 2016-2020. Thus, Indonesian Islamic scholars have become an important element in Indonesian society which has been concretely proven to make religious moderation a shared issue and commitment, as echoed by Indonesian Religion Ministers such as Lukman Hakim, Fachrul Razi, and Yaqut Cholil Qoumas.

\section{REFERENCES}

[1] Lukman Hakim Saifuddin, "Sambutan Menteri Agama Republik Indonesia" in Tim Penyusun Kementerian Agama RI. Moderasi Beragama. Jakarta: Kementerian Agama RI, 2019; Tim Penulis, Mozaik Moderasi Beragama dalam Perspektif Islam. Jakarta: Direktorat Jenderal Bimbingan Masyarakat Kristen Kementrian Agama Republik Indonesia, 2018.

[2]

http://diktis.kemenag.go.id/aicis/2018/index.php/201 8/10/05/ini-lima-poin-hasil-pertemuan-sarjanamuslim-dunia/ accessed on November 27, 2019.
[3]

http://diktis.kemenag.go.id/aicis/index.php/2019/10/0 6/aicis-2019-tiga-rekomendasi-sikapi-fenominadigital-islam/ accessed on November 27, 2019.

[4] https://lldikti12.ristekdikti.go.id/2012/02/01/surat-dirjendikti-no-152et2012-tentang-wajib-publikasi-ilmiahbagi-s1s2s3.html accessed on 27 November 2019.

[5] Fatimah Fatmawati, "Studi Penelitian Tafsir di Indonesia (Pemetaan Karya Tafsir Indonesia Periode 20112018)" in Al-Tadabbur: Jurnal Kajian Sosial, Peradaban dan Agama, Vol. 6, No. 1, 2020.

[6] Hariyah, "Research Trends in Islamic Studies on Journal of Research and Development and Training Center Ministry of Religious Affairs: Using Co-Words", in Record and Library Journal, Vol. 2, No. 2, 2016.

[7] Nailil Huda dan Ade Pahrudin, "Orientasi Kajian Hadis Kontemporer Indonesia (Studi Artikel E-Jurnal dalam Portal Moraref 2015-2017", in Refleksi, Vol. 17, No. 2,2018 .

[8] https://kbbi.kemdikbud.go.id/entri/moderasi dan https://lektur.id/arti-moderasi/ accessed on Oktober 26, 2020.

[9] https://kbbi.kemdikbud.go.id/entri/beragama accessed o Oktober 26, 2020.

[10] Departemen Agama RI. Etika Berkeluarga, Bermasyarakat dan Berpolitik. Jakarta: Lajnah Pentashihan Mushaf Al-Qur'an, 2009.

[11] Ali Muhammad Muhammad Al-Salabi, al-Wasathiyyah fi al-Qur'an al-Karim. Kairo: Maktabah At-Tabi'in, 2001.

[12] Mohammad Hashim Kamali, The Middle Pathof Moderation in Islam: the Qur'anic Principle of Wasathiyyah. New York: Oxford University Press, 2015.

[13] Tim Penyusun Kementerian Agama RI. Moderasi Beragama. Jakarta: Kementerian Agama RI, 2019.

[14] Tim Penyusun Kementerian Agama RI. Moderasi Beragama. Jakarta: Kementerian Agama RI, 2019.

[15] Darlis, "Mengusung Moderasi Islam di tengah Masyarakat Multi Kultural", in Rausyan Fikr, Vol. 13, No. 2, 2017.

[16] Muhammad Deny Irawan "Islam Wasatiyyah: Refleksi Antara Islam Modern dan Upaya Moderasi Islam", in Tajdid, Vol. XVI, No. 2, 2017.

[17] Nurul Faiqah and Toni Pranisiska, "Radikalisme Islam VS Moderasi Islam: Upaya Membangun Wajah Islam Indonesia yang Damai", in Al-Fikra: Jurnal Ilmiah Keislaman, Vol. 17, No. 1, 2018.

[18] Ahmad Fauzi, "Moderasi Islam, untuk Peradaban dan Kemanusiaan", in jurnal Islam Nusantara, Vol. 2, No. 2, 2018.

[19] Busyro, dkk, "Moderasi Islam (Wasathiyyah) di Tengah Pluralisme Agama Indonesia", in Fuadana: Jurnal Kajian Keagamaan dan Kemasyarakatan, Vol. 3, No. 1, 2019.

[20] Ahmad Khoiri, "Moderasi Islam dan Akulturasi Budaya: Revitalisasi Kemajuan Peradaban Islam Nusantara", in Islamadina: Jurnal Pemikiran Islam, Vol. 20, No. 1, 2019. 
[21] Khalil Nurul Islam, "Moderasi Beragama di Tengah Pluralitas Bangsa: Tinjauan Revolusi Mental Perspektif Al-Qur'an", in Kuriositas: Media Komunikasi Sosial dan Keagamaan, Vol. 13, No. 1, 2020.

[22] Mohammad Fahri and Ahmad Zainuri, "Moderasi Beragama di Indonesia", dalam Intizar, Vol. 25, No. 2, Desember 2019.

[23] Busyro, dkk, "Moderasi Islam (Wasathiyyah) di Tengah Pluralisme Agama Indonesia", in Fuadana: Jurnal Kajian Keagamaan dan Kemasyarakatan, Vol. 3, No. $1,2019$.

[24] Hamka Husein Hasibuan, "Moderasi Islam, Pencantuman Penghayat Kepercayaan di Kolom KTP/KK dalam Nalar Maqasid", in Al-Qalam: Journal of Islam and Plurality, Vol. 4, No. 2, 2019.

[25] RR. Wuri Arenggoasih and Corona Raisa WIjayanti, "Pesan Kementrian Agama dalam Moderasi Melalui Media Sosial Instagram", in Jurnalisa, Vol. 6, No. 1, 2020.

[26] Zakiyah Darajat, "Muhammadiyah dan NU: Penjaga Moderatisme Islam di Indonesia", in Hayulah: Indonesian Journal of Multidisciplinary Islamic Studies, Vol. 1, No. 1, 2017.

[27] Mustiqowati Ummul Fithriyyah and Muhammad Saiful Umam, "Quo Vadis Ormas Islam Moderat Indonesia? Menoropong Perang NU-Muhammadiyah di Era Revolusi Industri 4.0", in Politea: Jurnal Pemikiran Poltik Islam, Vol. 1, No. 1, 2018.

[28] Ahmad Agis Mubarok and Diaz Gandara Rustam, "Islam Nusantara: Moderasi Islam di Indonesia", in Journal of Islamic Studies and Humanities, Vol. 3, No. 2, 2018.

[29] A. Jauhar Fuad "Akar Sejarah Moderasi Islam pada Nahdlatul Ulama”, in Tribakti: Jurnal Pemikiran Keislaman, Vol. 31, No. 1, 2020.

[30] Darlis, "Peran Pesantren As'adiyah Sengkang dalam Membangun Moderasi Islam di Tanah Bugis (Sebuah Penelitian Awal)", in Al-Misbah, Vol. 12, No. 1, 2016.

[31] Neny Muth'iatul Awwaliyah, "Pondok Pesantren sebagai Wadah Moderasi Islam di Era Generasi Millenial", in Islamic Review: Jurnal Riset dan Kajian Keislaman, Vol. 8, No. 1, 2019.

[32] Saifudin Asrori, "Lanskap Moderasi Keagamaan Santri, Refleksi Pola Pendidikan Pesantren", in Jurnal Ilmu Sosial Indonesia (JISI), Vol. 1, No. 1, 2020.
[33] MA Hermawan, "Nilai Moderasi Islam dan Internalisasinya di Sekolah", in Insania, Vol. 25, No. $1,2020$.

[34] Hani Hiqmatunnisa and Ashif Az-Zafi, "Penerapan Nilai-nilai Moderasi Islam dalam Pembelajaran Fiqh di PTKIN Menggunakan Konsep Problem-Based Learning", in JIPIS, Vol. 29, No. 1, 2020.

[35] Nur Salamah, dkk, "Upaya Menyemai Moderasi Beragama Mahasiswa IAIN Kudus melalui Paradigma Ilmu Islam Terapan" in Quality, Vol. 8, No. 2, 2020.

[36] Muktafi, "Dinamika Pengarusutamaan Moderasi Islam di Masjid Nasional Al-Akbar Surabaya (MAS)", in Islamika Inside: Jurnal Keislaman dan Humaniora, Vol. 4, No. 1, 2018.

[37] Meirison, dkk, "Moderasi Islam dalam Kesetaraan Gender (Komparasi terhadap Agama Yahudi dan Nasrani)", in Jurnal Al-Ijtimaiyyah: Media Kajian Pengembangan Masyarakat Islam, Vol. 6, No. 1, 2020.

[38] RR. Wuri Arenggoasih, Corona Raisa Wijayanti, "Pesan Kementrian Agama dalam Moderasi Melalui Media Sosial Instagram", in Jurnalisa, Vol. 6, No. 1, 2020.

[39] Fahrurrozi and Muhammad Thohri, "Media dan Dakwah Moderasi: Melacak Peran Strategis dalam Menyebarkan Faham Moderasi di Situs Nahdlatul Wathan On-Line Situs Kalangan Netizen MuslimSantri”, in Tasamuh: Jurnal Komunikasi dan Pengembangan Masyarakat Islam, Vol. 17, No 1, 2019

[40] Ari Wibowo, "Kampanye Moderasi Beragama di Facebook: Bentuk dan Strategi Pesan", in Edugama: Jurnal Kependidikan dan Sosial Keagamaan, Vol. 5, No. 1, 2019.

[41] Muhammad Miftahuddin, dkk, "Moderasi Beragama dalam Situs tafsiralquran.id", in Islamika Inside: Jurnal Keislaman dan Humaniora, Vol. 6, No. 2, 2020.

[42] Abdul Syatar, dkk, "Darurat Moderasi Beragama di Tengah Pandemi Corona Virus Desease 2019 (Covid19)", in Kuriositas: Media Komunikasi Sosial dan Keagamaan, Vol. 13, No. 1, 2020.

[43] Dany Miftah M, dkk, "Membumikan Nilai-nilai Moderasi Agama di Masa Pandemi (dalam Perspektif IPS)", in Harmony, Vol. 5, No. 2, 2021 